Portland State University

PDXScholar

University Honors Theses

University Honors College

5-25-2019

Medicaid Patients' Use of Dental Benefits

Merit Roshdy

Portland State University

Follow this and additional works at: https://pdxscholar.library.pdx.edu/honorstheses

Part of the Dental Public Health and Education Commons, and the Public Health Commons Let us know how access to this document benefits you.

Recommended Citation

Roshdy, Merit, "Medicaid Patients' Use of Dental Benefits" (2019). University Honors Theses. Paper 831. https://doi.org/10.15760/honors.850

This Thesis is brought to you for free and open access. It has been accepted for inclusion in University Honors Theses by an authorized administrator of PDXScholar. Please contact us if we can make this document more accessible: pdxscholar@pdx.edu. 


\title{
Medicaid Patients' Use of Dental Benefits
}

\author{
by
}

Merit Roshdy

An undergraduate honors thesis submitted in partial fulfillment of the

requirements for the degree of

Bachelor of Science

in

University Honors

and

General Science

Thesis Adviser

Tina Burdsall, PhD.

Portland State University 


\title{
Roshdy, 1
}

\begin{abstract}
$\underline{\text { Abstract }}$
Oregon Health Plan patients experienced reduction to their dental coverage in 2003. This study explores Medicaid patients' use of those dental services that are still offered to them and the effect of their use on self-assessment of their oral health. A phone survey was conducted in 2017 and collected a sample of 293 Medicaid patients in Oregon. Only two thirds of participants reported that they have a regular dentist. Participants were more likely to rate their overall health as Excellent/Good when also rating their gum health as Excellent/Good. Low English Proficiency (LEP) patients were NOT less likely to visit their dentist.
\end{abstract}

\section{Background}

\section{Dental is Healthcare}

For years, dental care has been unreachable for many in the United States. During WWII, $10 \%$ of recruits to the US Armed Forces failed their oral health service requirements (Donoff et al., 2014). It was so concerning that President Harry Truman signed the National Dental Research Act in 1948, currently known as the National Institute of Dental \& Craniofacial Research. The goal of this act was "to improve the dental health of the people of the United States" (Donoff et al., 2014). Regardless of the efforts made by this act, Americans still struggle to receive dental care today; dental care has become a heavy cost to individuals (National Research Council, 2012). Furthermore, the lack of integration of oral care in medical coverage and the harmful separation between the mouth and the body as a whole led to heavy costs 
especially for those with chronic diseases such as diabetes and cardiovascular diseases (Jeffcoat et al., 2014; Donoff et al., 2014). In 2000, a Surgeon General's report on oral health revealed that issues such as gum inflammation may bring about major issues such as diabetes, heart and pulmonary diseases (Department of Health, 2000). In 2007, a 12-year-old boy from Maryland died due to untreated bacteria from a tooth infection that reached his brain (Donoff et al., 2014). This case received much attention from the legislature. Later, dental coverage became a requirement in the federal re-endorsement of Children's Health Insurance Program (CHIP) in 2009 (Donoff et al., 2014). This case only changed the law for children even though this could have happened to an adult.

Many studies have shown that dental/oral health is directly linked to overall health in both adults and children. For example, common medications used for blood pressure, asthma, and allergies can lead to impaired oral health. These medications can cause xerostomia, a medical term for chronically dry mouth (Dental Health, 2011). Individuals taking these medications and experiencing xerostomia are more prone to gum disease and cavities. However, those who visit their dentists can receive other prescribed medications that reverses the effect by increasing saliva flow in the mouth (Dental Health, 2011). Therefore, it is critical for those with chronic health issues to visit their dentist because medical health is linked to oral health.

Many studies have shown a possible relationship between periodontitis (gum disease) and cardiovascular disease (Kapellas et al., 2014; Jeffcoat et al., 2014). Although it is not clear whether periodontitis causes cardiovascular disease, in most cases, they both develop at the same 
time (Lockhart et al., 2012). A study of indigenous Austrilians has shown that severe periodontitis can cause arterial stiffness and eventually cardiovascular disease (Kapellas et al., 2014). The higher the severity of gum inflammation, the higher the likelihood of damaging the arterial structure (Kapellas et al., 2014). Good oral hygiene is also important for pregnant women. A study including 865 pregnant women showed that visiting the dentist and maintaining good oral hygiene is associated with less preterm birth and longer gestational age (Fogle et al., 2006). All in all, there is a clear link between dental health and overall health. The effect of dental health on the body as a whole and vice versa suggests that dental is indeed healthcare. A healthy body means a healthy oral cavity because in the end, the mouth is inseparable from the whole body.

\section{Oral Health-Related Quality of Life (OHrQoL)}

Oral Health-Related Quality of Life (OHrQoL) is defined as "a multidimensional construct that reflects (among other things) people's comfort when eating, sleeping and engaging in social interaction; their self-esteem; and their satisfaction with respect to their oral health" (Rockville, 2000: 7 as cited by Pillai et al., 2015). The OHrQoL is measured by the Geriatric Oral Health Assessment Index (GOHAI) (Pillai et al., 2015). OHrQoL measurements were created to determine the extent of oral health's effect on people's well-being and find ways to address oral issues. Some of the OHrQoL dimensions include physical disability, functional limitations, psychological disability, psychological discomfort, social disability, handicap, and physical pain (Hussain et al., 2010). A study of individuals who have problems with their dental 
dentures used the OHrQoL dimensions and found that denture problems significantly correlated with having many other problems affecting the body as a whole. These include feeling tense, interrupted meals, worsened taste, social irritability, poor diet, discomfort eating food, and inability to function (Hussain et al., 2010).

Those who belong to lower socioeconomic status are more likely to be associated with impaired OHrQoL (Foster et al., 2013). Impoverished children belonging to lower socioeconomic status may experience malocclusion (imperfect positioning of teeth), as they experience growth in the upper and lower jaw (Fernandez et al., 2018). Their problems are more likely to remain untreated due to the high cost of orthodontic treatment required for their malocclusion (Foster et al., 2013). Untreated malocclusion impacts the oral health in functions such as eating and speaking; not to mention the negative impact on their mental health and social behavior (Foster et al., 2013). Studies have shown that the OHrQoL of those with malocclusion problems has significantly improved after receiving the needed orthodontic treatment (De

Oliveira et al., 2004).

\section{Social Determinants of Health (SDoH)}

The health of individuals is determined by a number of social factors which are referred to as the Social Determinants of Health (WHO, 2008). Those determinants are categorized at the macro and micro levels. The macro level includes educational, economical, political, and racial discrimination conditions. It also includes micro level determinants such as behaviors, genetics, and healthcare (Mahamoud et al., 2013). Unfortunate social conditions can negatively influence 
the wellbeing of individuals. Poverty negatively impacts what people eat, where they live, and many other social conditions. In return, people's health is determined by those social conditions. For example, a decline in physical and mental health may be due to lack of income, education, nutrition, transportation, social support, and availability of healthcare (Sabato et al., 2018).

In 2016, the Federation Dentaire Internationale (FDI) representing more than 1 million dentists worldwide has adopted the SDoH as determinants of the oral health of individuals (Glick et al., 2016). The FDI believes that oral disease is linked to the social health of individuals and their overall health; "the mouth is both a cause and reflection of individual and population health and well-being" (Patrick et al., 2006: 1). According to studies, the mouth is a reflection of poor social health (Glick et al., 2016). Those belonging to lower socioeconomic levels are more prone to oral diseases (Glick et al., 2016). For example, low family income, race, and lack of maternal education increases the risk of dental caries in children (Yang et al., 2016). Other than being a reflection, the mouth can potentially be a cause of other major medical issues (i.e. cardiovascular disease) (Lockhart et al., 2012). Therefore, oral health is directly connected to the well-being of people and their overall health.

\section{Literature Review}

\section{Use of Dental Care}

Over 20 million Americans visit the dentist at least once a year but do not see a physician (Consumer Health News, 2011). A New York University investigation surveyed 31,000 adults, 


\section{Roshdy, 6}

$25 \%$ of those individuals did not visit a physician but did visit a dentist (Consumer Health News, 2011). These findings suggest that individuals seek dental care more frequently than medical care. Their need for dental care has led them to seek a dental provider more than other medical issues have led to seeking a physician. However, more studies show that insured and uninsured adults worry about the cost of care. About $50 \%$ of insured adults say they are "very" or "extremely" worried about additional costs of healthcare (Mundell, 2009). About 84\% of adults are concerned about raising the price of health insurance and are worried they will eventually become unable to afford it (Mundell, 2009). This becomes more concerning for low income individuals.

Many adults and children are covered under Medicaid, a national program providing healthcare to low-income individuals and families (DeLeire, 2011). In 2011, about sixty million Americans were covered under Medicaid for their medical and dental needs (Garfield et al., 2012). That is around one fifth of the United States population of 311 million in 2011. Although Medicaid is a national program, each state manages its own Medicaid program and decides whether dental benefits are included (Buchmueller et al., 2016). Moreover, states can also decide whether the dental coverage (if any) is full or partial (Buchmueller et al., 2016). The decrease in dental coverage, or lack thereof, has caused oral diseases to be the "neglected epidemic" (Wallace et al., 2011). According to the Affordable Care Act, Medicaid is required to provide dental benefits to children but not adults (Donoff et al., 2014).

\section{Medicaid in Oregon: Oregon Health Plan (OHP)}




\section{Roshdy, 7}

Oregon Health Plan (OHP) is the name of the Medicaid program in Oregon insuring low-income individuals and those who are ineligible for any other Oregon public insurance services (Baicker et al., 2013). OHP is split into two segments, OHP Standard and OHP Plus. Those who are covered under OHP Standard must have an income $100 \%$ below federal poverty level. On the other hand, OHP Plus covers those who are enrolled in federal services such as Temporary Aid to Needy Families (TANF) and those with disabilities (Wallace et al., 2011). In 2003, changes were made to the Oregon Health Plan Standard due to budget shortfalls. Those who were covered by OHP Standard no longer received full coverage for their dental care (Wallace et al., 2011). This has removed some major dental procedures from Medicaid coverage; OHP Standard enrollees are now asked to pay for preventive dental visits and costly procedures out of pocket (Wallace et al., 2011). In addition, copayments became a requirement with some dental appointments leading more OHP Standard enrollees individuals to skip their dental visits leaving them with unmet dental needs (Wallace et al., 2011). Major dental needs may be covered under OHP for Standard enrollees if it is considered an emergency (Wallace et al., 2011).

Changes to the OHP dental coverage left many seeking help from Emergency Departments (ED) (Cohen et al., 2003). In fact, seeking medical help or the ED for dental complaints has been an ongoing issue for years. Between the years 1997 and 2000, there were 2.95 million Emergency Department visits for dental pain (Lewis et. al., 2003). Members of OHP Standard have specifically increased their visits to the Emergency Department for their dental needs as a result of eliminating some dental benefits in 2003 (Wallace et al., 2011). OHP 
patients' visits to the ED do not replace the need for a dentist. Providers in the medical field have very little to no exposure to dental procedures and will most likely be of very little help to those in pain (Baicker et al., 2018). Most patients understand that a visit to a dentist is necessary even if financial barriers come in the way (Cohen et al. 2009). Some invest in oral health because they understand its importance in improving general health (Jeffcoat et al., 2014). They believe that it is worth spending money on a dental treatment that will actually solve the issue rather than seeking medical help for their teeth (Cohen et al., 2009). Other individuals may endure toothaches for years to avoid dental expenses by mostly relying on painkillers (Cohen et al., 2009, Carlson et al., 2008). Some even rely on home remedies such as guava leaves and garlic to relieve their dental pain and toothache (Cohen et al., 2009; Gilbert et al., 2000). This should not be the case for those with great dental needs. These problems should be addressed by a dental professional and classified as important as any other medical needs. The mouth is part of the human body therefore, it is part of the overall health of people.

\section{Issues with Medicaid Dental Benefits}

Changes to public health insurance impact both health providers and patients (Choi, 2011). Those who are covered under Medicaid rely on that coverage for their health needs. Medicaid enrollees receive coverage for ordinary dental procedures (e.g. tooth fillings) however, treatments including root canals, extractions, dentures, and other major dental procedures are not covered under Medicaid (Choi, 2011). Some treatments can cost thousands of dollars; one root canal can range from $\$ 500-1000$ (Carlson et al., 2008). Therefore, some patients have no choice 
but to rely on painkillers that are covered by Medicaid as a way to deal with their dental issues whose treatment may not be covered (Cohen et al. 2009).

There are also some dentists that will reject patients with Medicaid because they are paying less than private insurance for the same treatments (Decker, 2015). Rejection of Medicaid patients can be correlated with a noticeable decrease in care received by those patients (Decker, 2015). It was found that only 55\% of children under Medicaid were able to see a dentist in the past 6 months compared to $68 \%$ of children who are privately insured (Decker, 2015). This raises many concerns about how accessible dental treatment really is for Medicaid individuals.

\section{LEP and Medicaid}

There is a possible correlation between immigrants flow to the United States and number

of individuals covered by Medicaid. Medicaid enrollees more than doubled in the past couple of decades (Buchmueller et al., 2016). Their number increased from approximately $3.8 \%$ of the US population in 1975 to $8.5 \%$ in 2010 (Buchmueller et al., 2016). The time period between 1975 and 2010 has also seen the greatest number of immigrants in the United States. According to the Migration Policy Institute, the greatest flow of migrants to the US between 1820 to 2017 was during the time between 1988 to 1991(U.S. Immigration Trends, 2019). The number of legal residents in the US has increased by more than 650 thousand residents between the year 1975 to 2010 (U.S. Immigration Trends, 2019). According to HealthCare.gov, "lawfully present immigrants" are eligible to receive Medicaid as long as their income meets the rules of their states (HealthCare.gov, 2020). The majority of these immigrants come from non-English 
speaking countries and can be referred to as Limited English Proficiency (LEP) individuals. In fact, LEP makes up 9\% of the US population and 12\% of Medicaid enrollees (Gershon et al., 2016; Gonzalez, 2014).

Professional interpretation services are utilized to help overcome the language barrier between health providers and Limited English Proficiency (LEP) patients. Using a professional interpreter maintains a safe environment, insures equal treatment, and eliminates miscommunications in the health field (Leininger et al., 2006; Hadziabdic et al., 2014). Low-income individuals make up a large portion of LEP patients and it is important to provide them with reliable interpretational services (Shippee et al., 2012; Casey et al., 2004). In 2000, Executive Order 13166 required all health professionals to provide high-quality interpretation services for their Medicaid LEP patients (Shippee et al., 2012; Clinton, 2000; Lichtman, 1971). However, LEP patients still struggle to access high-quality interpreters as part of their healthcare (Elderkin-Thompson et al., 2001; Hsieh, 2010). Furthermore, issues may still arise even when a highly professional interpreter is provided. Most of the time, patients' illnesses are socially and culturally constructed introducing more than just a language barrier between providers and patients (Hsieh, 2010; Lawton, 2003). Patients' cultural backgrounds may affect their understanding of illness and that is something that is very difficult to be communicated between LEP patients and their health providers. Therefore, information delivered by interpreters to LEP patients may be distorted by the lack of cultural connection. 
Roshdy, 11

Patients of color tend to prefer to be seen by dentists that speak the same language or share the same race (Bender et al., 2007). This is referred to as Racial Concordance which has encouraged more dental and medical schools to have more racial diversity among their student body (Bender et al., 2007). Efforts have also been made to allow foreign-trained dentists to easily earn a license to practice in the United States to improve dentist-patient connection among some racial groups. However, there has been ethical issues associated with foregin-trained dentists that makes it difficult for them to gain a license (Bazargan et al., 2010). Encouraging foreign-trained dentists to practice in the United States deprives their countries' health systems from utilizing their skills to serve their populations. This can be referred to as "brain draining" of healthcare in foreign countries (Bazargan et al., 2010; Hooper, 2008).

Overall, many studies and literature emphasize the role of dentistry on the well-being of individuals. However, dentistry remains separated from healthcare and many still struggle to receive treatments for their oral needs. This study will focus on Medicaid enrollees' use of their dental benefits. The study explores the association of oral health with overall health in hope to bring more attention to the idea of dental as healthcare. There is limited literature on Medicaid enrollees' self assessment of their oral health and their overall health and this study aims to fill this gap in the literature. Another component to this study is LEP and its effect on patients. The study will explore whether LEP patients are less likely to understand and use the benefits provided to them through Medicaid, especifically OHP. 
Roshdy, 12

\section{Research Questions}

\section{How much does low-income patients' use of dental services through Medicaid affect their} dental health?

\section{Are Limited English Proficiency Medicaid enrollees less likely to visit the dentist?}

\section{Methodology}

To examine the use of Medicaid patients of dental services, a phone survey was conducted in 2017. Calls were made 3 times over the course of a week. If a member did not answer, another member was called until the 293 Medicaid members were reached (Burdsall, 2017). All participants were 18 years of age or older, eligible dental members of Oregon Health Plan (OHP), and have visited their dentist within the past 12 months. In this survey, participants were asked if they have a regular dentist and how they feel about the dental care they receive. They were also asked about the frequency of their visits to the dentist. The survey included questions like "When do you expect to make your next dental visit?" Participants were also asked if they utilized the emergency room or non-dental health care providers for their dental problems. The survey included questions that help determine the participants' self-assessment of their oral health as well as their overall health. They were asked to rank their health as Excellent, Very Good, Good, Fair, or Poor.

Data analysis assessed Medicaid enrollees' use of the dental benefits provided to them. How participants respond to the question about having a regular dentist helped determine Medicaid patients' use of coverage. Participants' expectations for when their next dental 
appointment should be was also factored into their use of benefits. It was also important to consider how the demographic information, especially race/ethnicity, can impact the participants' access to dental care.

There were two major parts to this study. The first part was to examine all participants' use of Medicaid dental services provided to them. The second part focused on the differences noticed between Medicaid enrollees who are English Proficient (EP) and those who have Limited English Proficiency (LEP).

\section{$\underline{\text { Results }}$}

The sample included 55.6\% $(n=163)$ females and 44.4\% $(n=130)$ males. Age ranged from 21 to 92 with the most participants being from 31 to 55 years old (48.3\%). Most participants were white (73.7\%) while the rest included African Americans, Hispanics, Asians, Pacific Islanders, and American Indians. About half of the participants have an education level of high school degree or GED (49.1\%) and the other half has at least some college (47.8\%). 
Table 1: Demographics

\begin{tabular}{|c|c|c|}
\hline & \# of Participants & $\%$ of participants \\
\hline \multicolumn{3}{|l|}{ Gender } \\
\hline Female & 163 & 55.6 \\
\hline Male & 130 & 44.4 \\
\hline \multicolumn{3}{|l|}{ Age } \\
\hline $21-30$ & 75 & 26.0 \\
\hline $31-55$ & 139 & 48.3 \\
\hline 56 or older & 74 & 25.7 \\
\hline \multicolumn{3}{|l|}{ Race } \\
\hline White & 216 & 73.7 \\
\hline Black & 28 & 9.6 \\
\hline Hispanic & 24 & 8.2 \\
\hline All others & 12 & 4.1 \\
\hline Refused to answer & 13 & 4.4 \\
\hline \multicolumn{3}{|l|}{ Education } \\
\hline $8^{\text {th }}$ grade or less & 6 & 2.0 \\
\hline Some high school & 6 & 2.0 \\
\hline High school/GED & 144 & 49.1 \\
\hline Some college & 98 & 33.4 \\
\hline 4-year college grad & 38 & 13.0 \\
\hline More than 4-years & 4 & 1.4 \\
\hline
\end{tabular}

Of all those surveyed, $10.1 \%$ were not aware or were unsure if they have dental benefits. When asked if they have a regular dentist, only $70.8 \%$ of participants answered "yes" while the 
remaining $29.2 \%(n=85)$ answered "no." Only $71.2 \%$ of participants expect their next dental visit to be within the next 12 months, while the rest $(28.8 \%, \mathrm{n}=84)$ do not expect it until over a year from the date of the survey. Only $3.1 \%(n=9)$ reported that they have been to the emergency room or to non-dental care providers for their toothaches. However, $8.3 \%$ reported that within the last 12 months, they needed dental care but did not receive it. When asked what services they needed, participants mostly reported they needed dentures, root canals, extractions, or replacement for missing teeth. Over one in every ten (11.8\%) reported that the cost of dental care is one of the reasons they avoid visiting their dentist. Most participants (94.5\%) do not avoid the dentist because they are embarrassed about their teeth or gums; only $5.5 \%$ said that was the case for them.

Some questions asked participants about the type of problems they had due to their dental issues. When asked if they have had any toothache within the past 12 months, $15.7 \%$ said they very often, often, or sometimes did experience pain. About $13.4 \%$ reported they have felt uncomfortable about the appearance of their teeth. Over a fifth $(20.9 \%)$ said they have avoided eating food due to problems with their teeth. About $13.1 \%$ have had trouble sleeping also due to problems with their teeth.

Table 2: Do you have a regular dentist or dental clinic?

\begin{tabular}{lll}
\hline & \# of participants & \% of participants \\
\hline Yes & 206 & 70.8 \\
No & 85 & 29.2 \\
Total & 291 & 100.0 \\
\hline
\end{tabular}


Table 3: Participants' expected visits to the dentist

\begin{tabular}{lcccc} 
& \multicolumn{2}{c}{ 6-12 months } & \multicolumn{2}{c}{ 1 to more than 5 years } \\
\hline & \# of participants & \% of participants & \# of participants & \% of participants \\
$\begin{array}{l}\text { When do you } \\
\text { expect your } \\
\begin{array}{l}\text { next dental } \\
\text { visit? }\end{array}\end{array}$ & 208 & 71.2 & 84 & 28.8 \\
\hline
\end{tabular}

Of those that do not have a regular dentist, 19\% ranked the overall condition of their teeth and gums as fair/poor. On the other hand, $23 \%$ of those who $\mathbf{d o}$ have a regular dentist also ranked their gum health fair/poor. Of all participants, $87.7 \%$ ranked their overall health somewhere between excellent and good. However, only 76.7\% ranked their dental health good to excellent. Association between the self-assessment of overall health and dental health was significant at the 0.01 level.

Table 4: Cross Tab Association between Self-assessment of overall and gum health Self-assessed Overall Health

\begin{tabular}{|c|c|c|c|c|c|}
\hline & & & $\begin{array}{l}\text { Excellent - } \\
\text { Good }\end{array}$ & Fair - Poor & Total \\
\hline \multirow[t]{4}{*}{$\begin{array}{l}\text { Self-Assessed } \\
\text { Gum Health }\end{array}$} & $\begin{array}{l}\text { Excellent - } \\
\text { Good }\end{array}$ & Count & 208 & 16 & 224 \\
\hline & & $\%$ & 81.3 & 44.4 & 76.7 \\
\hline & Fair - Poor & Count & 48 & 20 & 68 \\
\hline & & $\%$ & 18.8 & 55.6 & 23.3 \\
\hline \multirow[t]{2}{*}{ Total } & & Count & 256 & 36 & 292 \\
\hline & & $\%$ & 100.0 & 100.0 & 100.0 \\
\hline
\end{tabular}

Association is significant at the 0.01 level. 
Reports about primary language of participants showed that $10.7 \%$ speak a language other than English at home while the rest (89.3\%) speak English as their primary language. Of those who speak a language other than English, $80.6 \%$ have a regular dentist compared to $69.9 \%$ of Native English speakers. More LEP participants (87.1\%) are expecting to visit a dentist within the next 12 months relative to Native English speakers (69.3\%). Of all participants, $6.2 \%(\mathrm{n}=18)$ avoid the dentist because they believe that their dentists will not listen to them carefully. Only $22.2 \%(n=4)$ of those belong to the LEP group.

Table 3: The effect of LEP on participants' reception of care

\begin{tabular}{|c|c|c|c|c|}
\hline & \multicolumn{4}{|c|}{ Primary Language } \\
\hline & \multicolumn{2}{|c|}{ English Proficient (EP) } & \multicolumn{2}{|c|}{ Limited English Proficiency (LEP) } \\
\hline & \# of participant & $\%$ of participants & \# of participant & $\%$ of participants \\
\hline $\begin{array}{l}\text { Have a regular } \\
\text { dentist }\end{array}$ & 179 & 69.9 & 25 & 80.6 \\
\hline $\begin{array}{l}\text { Believe that } \\
\text { dentist will not } \\
\text { listen carefully }\end{array}$ & 14 & 5.4 & 4 & 12.9 \\
\hline $\begin{array}{l}\text { Avoid dentist } \\
\text { because of cost }\end{array}$ & 54 & 20.9 & 4 & 12.9 \\
\hline Afraid of dentist & 81 & 31.7 & 3 & 9.7 \\
\hline $\begin{array}{l}\text { Expect to visit the } \\
\text { dentist within the } \\
\text { next } 12 \text { months }\end{array}$ & 178 & $69.3^{*}$ & 27 & $87.1^{*}$ \\
\hline
\end{tabular}




\section{$\underline{\text { Discussion }}$}

\section{Health Status (Self-Assessment)}

Based on participants' self-assessments, gum health ratings were lower than the overall health rating. The correlation between overall health and gum health was significant at the level of 0.01 . This suggests that people who believe they are healthy overall, are more likely to rate their gum health higher than those who feel unhealthy overall. Close to three quarters (71.2\%) of participants rated both their gum health and overall health as Excellent/Good. The remaining quarter of participants rated their gum health and/or overall health as Fair/Poor. Poor ratings of oral health and/or overall health signal to Medicaid enrollees' need for health care whether that be dental or medical.

Participants are found to need dental care more than physical care (Consumer Health News, 2011). When looking at participants who rated their overall health highly, about one fifth (18.75\%) rated their gum health lower. On the other hand, only $7.1 \%$ of those who highly rated their gum health rated their overall health lower. Although there is an obvious association between oral health and overall health, it seems that those who think they have good gum health are more likely to think they also have good overall health. However, it is less likely for those who rated their overall health highly to also rate their gum health as Excellent/Good. When looking at all the participants, there were significantly less positive ratings for gum health compared to overall health. About a quarter (23.3\%) of all participants think their gum health is Fair/Poor compared to the $12.3 \%$ who believe their overall health is Poor/Fair. Whether these issues have been addressed by a dentist or not, this still confirms Medicaid population's need for dental care. It was great to see that many people $(87.7 \%)$ believe they have good overall health. 
However, the difference in ratings between overall health and gum health confirms the continued separation of dental care from health care. The lower ratings for gum health may be due to the recent reductions to OHP. It could also be due to the cost of care as $20.1 \%$ said they avoid the dentist due to the cost of dental care (Cohen et al., 2009; Carlson et al., 2008).

What was most surprising about the participants' rating of their gum health was seen in the cross tab. Of those who do not have a regular dentist, $81.0 \%$ ranked their gum health as Excellent/Good compared to $76.1 \%$ of those who do have a regular dentist. Those who do not have a regular dentist were expected to rank their gum health poorly. However, their higher ranking of their gum health may come from the belief that they are in no need of dental care. They may not be aware of their dental issues because they are not in pain, and they do not have a regular dentist to bring potential dental issues to their attention.

\section{Do You Have a Regular Dentist?}

Although participants were selected specifically for their Medicaid coverage, $10.1 \%$ were not aware of their dental benefits. The lack of knowledge may be a factor as to why those individuals are not visiting their dentists, assuming none of their care is covered by their insurance. All participants have been to a dentist within the last six to twelve months however, only $70.8 \%$ reported they have a regular dentist. Participants' visits to the dentist may be frequent due to their need for care but not necessarily due to their understanding of the importance of frequent check-ups (Baicker et al., 2018; Buchmueller et al., 2016). Most are utilizing the dental benefits provided to them for restorative and treatment reasons rather than preventive reasons. Only $71.2 \%$ of participants expect their visit to be within six to twelve months. This goes back to the idea that Medicaid patients are potentially lacking education about 
their oral health. Almost a third of participants appear not to understand that it is critical to visit their dentist at least once a year. Medicaid patients' need for dental care and lack of understanding their benefits may lead them to seek help from the wrong providers.

Although some of the literature heavily discussed Medicaid patients' use of emergency room and non-dental care for their teeth pain, this was not the case for this sample (Cohen et al., 2009, Baicker et al., 2018). Only 3.1\% reported they have been to the emergency room for their toothache problems within the last 12 months. However, it is important to note that a greater number $(8.3 \%, \mathrm{n}=24)$ claimed that they needed dental care but did not get it within the last 12 months. This number may be passed unnoticed because it is very small, but that is almost one in every ten Medicaid patients in this sample that needed care but did not get it. Most of those who reported they did not receive care when they needed it also reported their unmet need for dentures, root canals, and extractions, those of which are not fully covered by Medicaid (Cohen et al., 2009). Although numbers are small, it is important to recognize that these are issues that do exist for some patients. Not having these issues resolved and not receiving the needed treatments may lead some to rely on home remedies and other unhealthy habits that may temporarily relieve their pain but potentially lead to major health issues (Cohen et al., 2009; Gilbert et al., 2000).

Although percentages were not very high, a good amount of participants have experienced poor OHrQoL (Rockville, pg. 7, 2000; Pillai et al., 2015). Not being able to do simple tasks such as sleeping or eating is something that should be addressed. With about a fifth of the sample having eating problems, and $13.1 \%$ having trouble sleeping, these individuals' dental problems have greatly hindered their well-being. Therefore, it is necessary to address such 
problems because they can easily lead to rather major problems affecting individuals' overall health and well-being (Hussain et al., 2010).

There was also a good amount of participants (15.7\%) that reported having toothaches within the past 12 months. Although that does not indicate whether going to the dentist helped relieve the pain, it is an indicator that Medicaid enrollees are in need of care. Such problems are also affecting the quality of life for those people; dental needs impact patients both physically and socially. As discussed above, some have physical problems such as trouble sleeping and/or eating. However, $13.4 \%$ of participants reported feeling uncomfortable about the appearance of their teeth, mouth, or dentures within the last 12 months; $6.9 \%$ have avoided visiting the dentist due to their embarrassment of their teeth/gums appearance. These issues have been shown to affect patients on the psychological and mental level as well. Therefore, dental problems can be the cause of poor quality of life to those experiencing them (Hussain et al., 2010; Rockville, Pg. 7, 2000; Pillai et al., 2015).

\section{Limited English Proficiency (LEP) Participants}

Communication between dentists and their patients are critical for ensuring the return of patients for future visits. A very small percentage (6.2\%) said they avoid dental visits because they do not think the dentist will listen to them carefully. Although this is a good indicator that most people experience good patient-dentist relationships, others such as LEP individuals may be expected to struggle.

Most of the participants (89.3\%) reported English as their primary language, but some differences were seen when comparing to LEP participants. Non-English speakers were more likely to have a regular dentist compared to English speakers (80.6\% vs $69.9 \%)$. Although there 
was no significant correlation here, a link can be made between having a regular dentist and expectation for the next dental visit. Relative to English speakers, more LEP Participants have a regular dentist, and also more of them are likely to expect their next dental visit to be within the next 12 months. LEP patients may utilize interpreting services provided to them during a dental visit to schedule the next visit (Hsieh, 2010; Lawton, 2003). One of the reasons non-English speakers migrate to the United States is to seek better health opportunities (Gonzalez, 2014). Therefore, perhaps their first instinct is to visit health professionals and dentists for check-ups. Communication between dentists and participants was mainly analyzed based on participants' response to the question: "Do you avoid dental visits because you believe the dentist will not listen carefully?" There was a total of $6.2 \%(n=18)$ that believed their dentists would not listen to them. Although most of these participants ( $n=14)$ come from the EP group, it only represented $5.4 \%$ of the EP sample. On the other hand, $12.9 \%(\mathrm{n}=4)$ of LEP patients believe their dentists will not listen carefully. Although none of the survey questions asked participants about their use of interpretation services, it is concerning to find that over one in ten LEP patients in this sample do not find their dentists listening carefully to them. Even if those people actively use interpretation services, this issue may be due to the quality of interpretation provided to them. Their interpreter may not convey all their concerns to their dentist and therefore dentists are not fully aware of these concerns (Elderkin-Thompson et al., 2001; Hsieh, 2010). Consequently, dentists will not address these issues. This lack of communication may lead LEP patients to think their dentist will not listen carefully to them and find it useless to have their dental visits. 
Because Medicaid patients may not speak, read, or write English fluently as others, they may not be utilizing the brochures or flyers posted regarding the importance of oral health. Many are not used to the preventative care as they are coming from other countries where oral health is not utilized as much for preventative as it is used more for restorative. Another reason could be that they are only visiting the dentist when home remedies fail or only when pain occurs (Gonzalez, 2014; Cohen et al., 2008; Carlson et al., 2008).

The idea of Social Determinants of Health $(\mathrm{SDoH})$ is especially important for LEP patients. Those individuals' race differences and their discomfort with speaking the English language can place them in a disadvantage. Although they might be utilizing interpretation services to better communicate with their dentists, cultural barriers remain an issue (Hsieh, 2010; Lawton, 2003). Patient-dentist communication will be negatively affected through such barriers and hindering optimal healthcare to LEP patients.

\section{Conclusion}

OHP participants need education about their Medicaid dental benefits. Some were not aware they had any dental benefits. Others did not expect to utilize these benefits when they are supposed to. Therefore, we can answer the question of how much low-income patients' use of dental services affect their dental health. Through participants' self assessment of their gum health, it was clear that many realized their oral health needs more attention. All participants have been to the dentist within the last 12 months and that is why they were surveyed, however, not all of them seem to understand how to use their dental services. Therefore, the question 
should really be whether their understanding of how to use dental services affect their dental health, and in that case it does. Less than three quarters have a regular dentist and the rest do not. This can be due to the lack of preventative coverage for some OHP patients who are enrolled in OHP Standard (Wallace et al., 2011). Therefore, dental care may be seen as a restorative resource rather than a preventative one due to cost for some enrollees.

The correlation between the assessment of overall health and gum health suggests a strong link between the two. Medicaid patients' unmet dental needs can also affect their overall health and make them more prone to serious diseases (Hussain et al., 2010). Therefore, financial limitations that have affected the Medicaid dental benefits are indirectly affecting people as a whole.

LEP participants were more likely to visit the dentist according to data. However, they were also more likely to feel their dentist will not listen to them. Their reports back to their dentist for check ups may be due to someone else such as their interpreter holding them accountable for scheduling their next visit. However, it remains concerning that LEP individuals feel they are not heard because it may eventually lead them to avoid visiting their dentist.

A limitation to this study was that it was only provided in English. This gave a disadvantage to LEP participants and may have led to miscommunication and misunderstanding of survey questions. For future surveys, it will be advantageous to provide translated versions of the survey to ensure a more accurate data collection and be more inclusive of LEP participants. Moreover, asking participants questions over the phone may lead them to pick the "right answer" 
Roshdy, 25

rather than an honest response to questions. Therefore, having a written survey translated into multiple languages will help improve the diversity and accuracy of results providing optimal results. 


\section{Bibliography}

Ansarian, A, \& Khosravi, M. (2016). Emphasizing the Correlation of Periodontal Diseases with Cardiovascular Disorders in the Educational Curriculum of Dental and Medical Students. Educational Research in Medical Sciences,3(2), 35-36.

Baicker, K., Allen, H. L., Wright, B. J., Taubman, S. L., \& Finkelstein, A. N. (2018). The Effect of Medicaid on Dental Care of Poor Adults: Evidence from the Oregon Health Insurance Experiment. Health Services Research, 53(4), 2147-2164.

Bazargan, N., Chi, D. L., \& Milgrom, P. (2010). Exploring the potential for foreign-trained dentists to address workforce shortages and improve access to dental care for vulnerable populations in the United States: A case study from Washington State. BMC Health

\section{Services Research, 10.}

Bender, D. J., \& Ed, D. (2007). Patient Preference for a Racially or Gender-Concordant Student Dentist. Journal of Dental Education, 71(6), 726-745.

Buchmueller, T., Miller, S., \& Vujicic, M. (2016). How do providers respond to changes in public health insurance coverage? Evidence from adult medicaid dental benefits.American Economic Journal: Economic Policy, 8(4), 70-102.

Burdsall, T. (2017). Report. Unpublished research.

Carlson, J. P., Huppertz, J. W., Neidermeyer, P. E., Carlson, J. P., Huppertz, J. W., Neidermeyer, P. E., ... Neidermeyer, P. E. (2008). Price and Consumer Cost Responsibility Effects on Quality Perceptions and Price Negotiation Likelihood for Healthcare Services, 9683. 
Casey, M., Blewett, L., \& Call, K. (2004). Providing Health Care to Latino Immigrants: Community-Based Efforts in the Rural Midwest. American Journal of Public Health, 94(10), 1709-11.

Clinton, W. (2000). Executive Order 13166: Improving access to services for persons with limited English proficiency, August 11, 2000. Weekly Compilation of Presidential Documents, 36(32), 1852-1853.

Cohen, L., Harris, S., Bonito, A., Manski, R., Macek, M., Edwards, R., Khanna, N., Plowden, K., (2009). Low-income and minority patient satisfaction with visits to emergency departments and physician offices for dental problems. The Journal of the American College of Dentists, 76(3), 23-31.

Consumer Health News. Dentists Could Fill Gap in Health Care, Study Says; Many Americans who make dental visits don't get routine medical care. (2011). Consumer Health News (English), p. Consumer Health News (English), Dec 15, 2011.

Decker, S. (2015). Medicaid Payment Levels to Dentists. Journal of American Medical Assosication, 306(2), 187-193.

DeLeire, T., Lopoo, L., \& Simon, M. (2011). Medicaid Expansions and Fertility in the United States. Demography, 48(2), 725-747.

Dental health and overall hearth become increasingly linked as we age. (2011). The Dental Assistant, 80(2), 42 . 
Department of Health, Human Services, Washington, DC., \& Healthy People 2010 (Group). (2000). Healthy people 2010: Understanding and improving health. US Department of Health and Human Services.

De Oliveira, C. M., \& Sheiham, A. (2004). Orthodontic treatment and its impact on oral health-related quality of life in Brazilian adolescents. Journal of orthodontics, 31(1), $20-27$.

Donoff, Bruce, McDonough, John E., \& Riedy, Christine A. (2014). Integrating oral and general health care. The New England Journal of Medicine, 371(24), 2247-2249.

Elderkin-Thompson, V., Cohen Silver, R., \& Waitzkin, H. (2001). When nurses double as interpreters: A study of Spanish-speaking patients in a US primary care setting. Social Science \& Medicine, 52(9), 1343-1358.

Fernandez, C., Pereira, C., Luiz, R., Vieira, A., \& De Castro Costa, M. (2018). Dental anomalies in different growth and skeletal malocclusion patterns. The Angle Orthodontist, 88(2), 195-201.

Fogle, D., Kershaw, T., Dobak, W., Lindsay, M., Westdahl, C., Ickovics, J., \& Rising, S. (2006). Effect of dental hygiene and overall health behavior during pregnancy on preterm birth and length of gestation. American Journal of Obstetrics and Gynecology, 195(6), S52.

Foster Page, L., Thomson, W., Ukra, A., \& Farella, M. (2013). Factors influencing adolescents' oral health-related quality of life (OHRQoL). International Journal of Paediatric Dentistry, 23(6), 415-423. 
Garfield, R., \& Damico, A. (2012). Medicaid expansion under health reform may increase service use and improve access for low-income adults with diabetes. Health Affairs (Project Hope), 31(1), 159-67.

Gershon, R., Morris, L., Ferguson, W., Goodwin, M., \& Washington, H. (2016). Including Language Access into Medicaid ACO Design. The Journal of Law, Medicine \& Ethics, 44(3), 492-502.

Gilbert, G., Stoller, E., Duncan, R., Earls, J., \& Campbell, A. (2000). Dental self-care among dentate adults: Contrasting problem-oriented dental attenders and regular dental attenders. Special Care in Dentistry : Official Publication of the American Association of Hospital Dentists, the Academy of Dentistry for the Handicapped, and the American Society for Geriatric Dentistry, 20(4), 155-63.

Glick, M., Williams, D. M., Kleinman, D. V., Vujicic, M., Watt, R. G., \& Weyant, R. J. (2016). A new definition for oral health developed by the FDI World Dental Federation opens the door to a universal definition of oral health. British dental journal, 221(12), 792.

Gonzalez, G. (2014). State Estimates of Limited English Proficiency (LEP) by Health Insurance Status. State Health Access Data Assistance Center.

Hadziabdic, E., Albin, B., \& Hjelm, K. (2014). Arabic-speaking migrants' attitudes, opinions, preferences and past experiences concerning the use of interpreters in healthcare: A postal cross-sectional survey. BMC Research Notes, 7(1), 71. 
Health coverage for lawfully present immigrants. (2020). Retrieved from

\section{https://www.healthcare.gov/immigrants/lawfully-present-immigrants/}

Hooper, C. (2008). Adding insult to injury: The healthcare brain drain. Journal of Medical Ethics, 34(9), 684-687.

Hussain, Syed Zahid, Shujaat, Nazli Gul, Idris, Shujaat Hasan, \& Chatha, M. Rafique. (2010). ORAL HEALTH RELATED QUALITY OF LIFE (OHRQOL) IN 40 TO 70 YEARS. Pakistan Oral and Dental Journal, 30(2), N/a.

Jeffcoat, M. K., Jeffcoat, R. L., Gladowski, P. A., Bramson, J. B., \& Blum, J. J. (2014). Impact of periodontal therapy on general health: evidence from insurance data for five systemic conditions. American journal of preventive medicine, 47(2), 166-174.

Kapellas, K., Jamieson, L., Do, L., Bartold, P., Wang, H., Maple-Brown, L., . . Skilton, M. (2014). Associations between periodontal disease and cardiovascular surrogate measures among Indigenous Australians. International Journal of Cardiology, 173(2), 190-196.

Lawton, J. (2003). Lay experiences of health and illness: past research and future agendas. Sociology of health \& illness, 25(3), 23-40.

Lewis, C., Lynch, H., \& Johnston, B. (2003). Dental complaints in emergency departments: A national perspective. Annals of Emergency Medicine, 42(1), 93-99.

Lichtman, E. (1971). Title VI of the Civil Rights Act of 1964. Civil Rights Digest, 4(2), 25. Lockhart, P. B., Bolger, A. F., Papapanou, P. N., Osinbowale, O., Trevisan, M., Levison, M. E., \& Wilson, W. R. (2012). Periodontal disease and atherosclerotic vascular disease: does 
the evidence support an independent association? A scientific statement from the American Heart Association. Circulation, 125(20), 2520-2544.

Mahamoud, A., Roche, B., \& Homer, J. (2013). Modelling the social determinants of health and simulating short-term and long-term intervention impacts for the city of Toronto, Canada. Social Science \& Medicine, 93, 247-255.

Mundell, E.J. (2009). Most Insured Adults Worry About Health Care Costs: Poll; Many are skipping medical, dental visits because of financial concerns. Consumer Health News (English), p. Consumer Health News (English), March 9, 2009.

National Research Council. (2012). Improving access to oral health care for vulnerable and underserved populations. National Academies Press.

Patrick, D. L., Lee, R. S. Y., Nucci, M., Grembowski, D., Jolles, C. Z., \& Milgrom, P. (2006, June). Reducing oral health disparities: a focus on social and cultural determinants. In BMC oral health (Vol. 6, No. S1, p. S4). BioMed Central.

Pillai, R., Mathur, V., Jain, V., Shah, N., Kalra, S., Kumar, P., \& Dey, A. (2015). Association between dental prosthesis need, nutritional status and quality of life of elderly subjects. Quality of Life Research, 24(12), 2863-2871.

Rockville, Maryland: US Department of Health and Human Services, National Institute of Dental and Craniofacial Research, National Institute of Health. (2000). DHHS oral health in America: A report of the surgeon general, p. 7. 
Sabato, E., Owens, J., Mauro, A., Findley, P., Lamba, S., \& Fenesy, K. (2018). Integrating Social Determinants of Health into Dental Curricula: An Interprofessional Approach. Journal of Dental Education, 82(3), 237-245.

Shippee, N., Pintor, J., Mcalpine, D., \& Beebe, T. (2012). Need, Availability, and Quality of Interpreter Services among Publicly Insured Latino, Hmong, and Somali Individuals in Minnesota. Journal Of Health Care For The Poor And Underserved, 23(3), 1073-1081.

U.S. Immigration Trends. (2019, December 18). Retrieved from https://www.migrationpolicy.org/programs/data-hub/us-immigration-trends\#history

Wallace, N. T., Carlson, M. J., Mosen, D. M., Snyder, J. J., \& Wright, B. J. (2011). The individual and program impacts of eliminating medicaid dental benefits in the Oregon Health Plan. American Journal of Public Health, 101(11), 2144-2150.

WHO Commission on Social Determinants of Health. (2008). Closing the gap in a generation : Health equity through action on the social determinants of health : Commission on Social Determinants of Health final report. Geneva, Switzerland: World Health Organization, Commission on Social Determinants of Health.

Yang, A. J., Gromoske, A. N., Olson, M. A., \& Chaffin, J. G. (2016). Single and cumulative relations of social risk factors with children's dental health and care-utilization within regions of the United States. Maternal and child health journal, 20(3), 495-506. 